CP, 2020, Vol.9 - No19, pp. 25/39 ISSN 2014-6752. Girona (Catalunya). Universitat de Girona. DUDA, T.: Virtualization of experience - Evaluating new communication tools in tourism and guiding. Recibido: 26/10/2020 - Aceptado: 23/11/2020

\title{
Virtualization of experience - Evaluating new communication tools in tourism and guiding.
}

\author{
AUTOR: \\ Tomasz Duda \\ University of Szczecin / Poland \\ Institute of Spatial Management and Socio-Economic Geography \\ tomasz.duda@usz.edu.pl
}

\begin{abstract}
In the modern world, tourism is perceived as the sphere of the most frequent meetings between representatives of different cultures. The result of intensive traveling and frequent entry into the space of unknown civilizations, they become unprecedented challenges on such a large scale. They include, among others the effectiveness of communication outside of one's own culture, as well as the ability to interpret and sustainably promote cultural and natural spaces, which are increasingly used by the rapidly globalizing tourism market.
\end{abstract}




\section{Introduction}

In the modern world, tourism is perceived as the sphere of the most frequent meetings between representatives of different cultures. The result of intensive traveling and frequent entry into the space of unknown civilizations, they become unprecedented challenges on such a large scale. They include, among others the effectiveness of communication outside of one's own culture, as well as the ability to interpret and sustainably promote cultural and natural spaces, which are increasingly used by the rapidly globalizing tourism market.

The progressive unification of tourist services and the rapid development of mass tourism in the second half of the 20th century forced the need for a professional interpretation of the destination and the introduction of a suitably qualified person (guide, interpreter, tour-leader) as an intermediary in the cultural dialogue between the destination and the recipient (tourist). It acts as a specific 'decoder' of the cultural signal sent by the emitter (tourism space). Thanks to his social, linguistic and educational competences, through the use of appropriate narration, targeted storytelling, as well as adequate interpretation tools, he is a kind of mediator, a communication specialist, serving both sides of the dialogue - sender of the cultural code and the recipient, tourist. It is at the same time a creator of dialogue and an 'information filter' in many cases limiting or even preventing the emergence of conflicts and socio-tourist dysfunctions.

A tourist guide, or to consider a bit more broadly - an interpreter of tourism space, apart from the aforementioned competences of communication, dialogue and understanding of the intercultural code, is a real intermediary between the visited place and the visitor. It not only provides reliable information about the history, geography and cultural traditions of a place, but also allows you to understand their meaning, functions in the modern world and feel the immaterial atmosphere of the place, its genius loci along with positive and negative factors that shape it. The right interpreter contributes more to the experience of places than just the classical assimilation of information and passive exploration of space. According to the Dale's "Cone of Experience" (Fig .1.), the more we are involved in creating an idea, the more we remember and learn the set goal. One of the most effective forms of communication in tourism is the involvement of the recipient (in this case a tourist) in various activities, as well as encouraging them to think and discuss for themselves. Professional interpreters, through the use of modern communication and interpretation tools, have been creating a new platform for dialogue for many years, allowing not only to explore new spaces, but above all to understand and properly perceive them on the social, cultural and religious levels. 


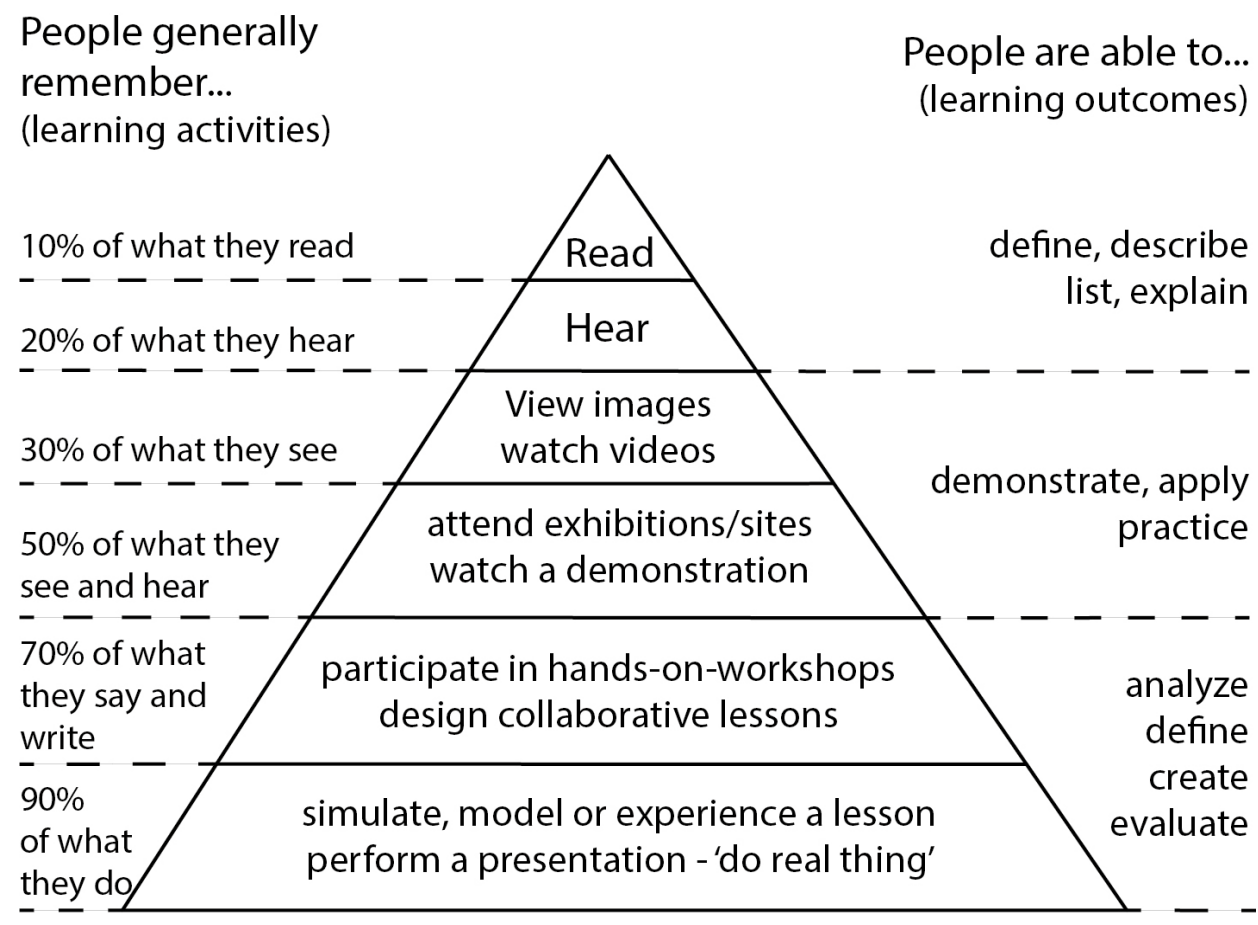

\section{Edgar Dale's Cone of Experience (Learning)}

Fig.1. Edgar Dale's Cone of Experience. The source: own work after Wikipedia

One of the most popular interpretation tools in contemporary tourism is virtual guidance and the use of modern technologies (including augmented and virtual reality, interactive maps, etc.) to interpret tourism spaces. It should also be emphasized that this rapidly developing form of communication in tourism dates back to the early 2000 s and is not related only to global (or even on a smaller scale) crisis situations, such as the current time of the covid-19 pandemic. Initially, as a tool supporting local interpreters and guides, it systematized the recipient's knowledge and enriched it with information about places or objects previously unknown and inaccessible. Over time, the tool has evolved into a separate form of narrative sightseeing, and thus an excellent interpretive tool for tourist guides, museum professionals or administrators of cultural and natural heritage sites. However, while for a long time this form of interpretation was used by a few and played the role of a somewhat exclusive tool, recently - due to the coronavirus pandemic, global isolation and a huge crisis in the outgoing tourism industry, the virtual leadership has largely taken over the functions of the interpreter tourist destinations and has commonly become a tool for creating intercultural dialogue in a closed space.

However, questions remain, the answers of which the author tries to find in the research process presented in this article. Is the virtual experience of a destination able to replace the tourist's direct contact with the surrounding reality and to what extent? In spite of the indisputable value and communication 
possibilities of this tool, does its use not deprive the visited place of authenticity? How does virtual interpretation build or eliminate barriers that prevent full understanding and mutual recognition between the sender (space) and the recipient (tourist)? Ultimately, it is worth considering the main problem - is the virtualization of tourist experiences conducive to the development of intercultural dialogue and contributes to mutual understanding and thus the sustainable development of tourism? The author additionally supported his considerations with his own original case studies, resulting from the work of a tourist guide and heritage interpreter.

\section{Construction of the paper and methodology}

The presented paper consists of three parts. The first one (theoretical one) presents the process and significance of communication competency in tourism interpretation. The analysis was based on contemporary knowledge and global literature available on the subject. Thus, the role of tour guide interpretation of the destination as well as its narrative tools were approached.

The second part shows the whole process of communication in tourist guides' interpretation as an information "stream" leading from the emitter (tourist space) to the recipient (tourist, visitor). The author's proposal was based on his experience in guiding as well as other tourist guides' perception on the communication process. It has been presented within three ways of information flow - with 'classic' interpreter (tourist guide or any type of informant), with virtual interpreter as well as with different virtual interpretation tools. This part of research was undertaken using the expert interview method as well as literature review. The model of communication process in tourist interpretation concludes the opinion of more than 20 tourist guides and interpreters surveyed across this research. Additionally, the relation between virtual interpretation and authenticity preservation was analyzed within this part of the paper.

The third, final part concerns the case study related to perception of the destination based on examples from Polish groups travelling to Girona (Catalonia/Spain). The perception varies depending on the form of travel and communication way (narrative tools) used by interpreter, tour-leader or tourist guide. Similar to analysis and research conducted within the second part of the publication, the methods of social surveys were conducted to obtain the right results and conclusions. Based on the author's own guiding experience during numerous travels to Girona as well as virtual tour providing, more than 450 visitors and more than 100 virtual 'tourists' were surveyed and asked to present their perception. In author's opinion these observations may relate to the information (communication) process' readability. It will let ones to understand the right reception of the information depending on level of virtuality used within the interpretation.

Communication competency in tourism and the role of tour guide in interpretation of destination Despite the fact that we share different information on a daily basis, we are rarely aware of the deeper dimensions of communication processes. We usually become aware of them only when there is a situation of mutual incomprehension that may lead to a conflict. Communication is a symbolic process consisting mainly in the mutual relationship between the sender of the message and its recipient. The sender determines the meaning of words, gestures, symbols, information or behaviors, and the recipient should "decode" them appropriately and receive their original message through understanding. As many researchers have already noted [incl. Spitzberg, Cupach 1998; Ting-Toomey 1999; Wilson, Sabee 2003 or Banaszkiewicz 2011] in the communication process, each participant brings their baggage of individual experiences, meanings, meanings, expectations and intentions. They may be an obstacle or a factor contributing to the success of communication and understanding of the transmitted and received content. 
A qualitatively better and more complete act of communication is facilitated by the participants' developing intercultural communication competence. This term, which appeared already in the 70s of the last century [incl. Harris 1979], defines one of several competences that a person acquires, has and develops during his life, in addition to, for example, linguistic or social competence. Communication competences in the work of an interpreter or a tourist guide were defined, among others, by Ricard [1993], Redmond [2000] and Beamer [1992] as:

„....natural or acquired aptitude of an individual or a group that enables understanding through verbal or non-verbal exchanges (...) it depends on the balance of complexity and flexibility between their own interpersonal system and the interpersonal environment (...)" [Ricard 1993]

"person's ability to encode and decode meanings that correspond to those meanings in the other communicator's repository (...)" [Beamer 1992].

Persons who constantly interact with intercultural dialogue are the tour guides, whose the main task is the permanent work with the interaction of different cultural backgrounds. To communicate optimally with their international visitors, tour guides need to understand the way in which cultural factors might affect the experience. Many researches recognize communication competency as an important quality and attribute for tour guides [e.g. Cohen 1985; Leclerc, Martin 2004; Zhang, Chow 2004; Al Jahwari, Sirakaya-Turk, Altintas 2016; Topler at all 2017]. They even state that the communication competency affects the overall perceived success or failure of tourist's experience. Their interpretation plays then a key role in the perception of an attraction or visited destination. As evidenced in Brochu \& Merriman's research "the tourism world relies on interpersonal communication and tour guides help visitors understand the meaning of the destination..." [Brochu, Merriman 2008].

Tourist guiding has an important and multifaced role in contemporary tourism. What they present and the way how they are doing this take effect on their customer's experience destination, understand local culture, engage in local activities and how they behave on the spot. As front-line professionals, information-givers and interpreters, the guides act as destination's representatives and 'ambassadors' of the place in the eye of visitors [Rabotic 2010]. The pioneer of making guiding a matter of scientific attention - Erik Cohen [1985], states that:

"... the role of professionals guides consists of two components: social mediation and cultural brokerage. In the first case, it is all about the mediator's role being in direct contact both with tourists and the local community, whereas in the second, the mediation in comprehending different cultures is in question (...)" [after: Rabotić 2010]

Moreover, Cohen indicates the significance of interpretation identifying that term with intercultural communication, explaining it as 'translation' of unknown elements of the host culture into a cultural 'code' mentally close to the visitor. It is important especially in the case when tourists spend only a short time at a destination and experience their temporary space from a leisure perspective of tourist activity. During the visit, guests are confronted by images or objects often unfamiliar to them, and its meaning must be professionally and complexed interpreted. The word 'interpretation' itself was recognized by Tilden directly to tour guiding as an educational activity aimed at revealing meanings and relationship to people [Tilden 1957]. Ap and Wong [2001] believe that tour guides through their familiarity and close relations with destination's attractions as well as communication competency can transform ordinary tourist's visit 
to memorable experiences. Other researches even state that guides and their communication skills may make or break a tour [e.g. Al Jahwari, Sirakaya-Turk, Altintas 2016; Luoh, Tsaur 2014]. Summarizing, besides the main role of the guide is to provide information, the communicative elements play an important role in shaping the relationship between the visitor and the destination - with its culture, environment, social identity, symbols and individual message.

Taking in account the scope of guides' competences, communication skills and their importance for the promotion of destination as well as creating the intercultural dialogue, blurring boundaries and breaking disfunctions, there are more than often when guide's service has been perceived as extremely neglected activity [e.g. Irigüler, Güler 2016; Mak, Wong, Chang 2011]. Some researchers say that tourist guides:

"represent a largely underrated, undervalued and underutilized human resource despite the widely acknowledged benefits and significant roles they assume in the tourist system" [Dioko, Unakul 2005].

The tour guides usually have frequent, extended and mostly intensive encounters with people who participate in tours and are expected to display diverse emotions. They are extremely responsible for achieving higher levels of customer satisfaction and turn tourist's excursion into a most pleasurable and unforgettable experience. That is why the tour guiding is often called 'Cinderella of tourism' [Irigüler, Güler 2016].

\section{Virtual experience as the communication tool - contradiction or complementarity?}

Tourism, as global social phenomenon, has been changing over time. This process still continues, and contemporary tourists expect to get personalized access to tourism information at anytime, from anywhere and through any media. As Wijesuriya and his research team [2013] have noticed:

"... with the advancement of technology, mobile devices have made it easier to access information anytime, anywhere. The trend is to replace the printed tour guides with mobile applications..." [Wijesuriya et al. 2013].

Self-contained, programmed applications, tutorials, drills, simulations, tests or virtual walks represent a new approach not only to wide understood tourism space but also to tourism phenomena at all. The low cost and easy use of semi-immersive virtual reality environments have recently caused this technology to experience a very fast expansion all over the world. It is generally agreed upon that there are many characteristics or attributes that make virtual technology a unique and potentially very useful educational tool. According to Crosier at al. [2002] they include not only visualization and presentation of invisible or not accessible spaces (objects) as well as ability to take on their different perspectives, anytime and from anywhere, but also many factors used in guiding or interpreting in tourism, like real-time interaction, flexibility of time, place and economy, exploring in dangerous situations etc. Moreover, it could be used by huge amount of people at the same time, without any social, cultural and even linguistic barriers. It is a multi-user space where visitors can "fly" around the places, go inside objects and, sometimes, set them in motion. Virtual tourists can bring the details closer and quickly compare them with other similar places in the region or anywhere else.

Is the virtual tour itself a professional interpretation? Is it capable of replacing the real man, presenting authenticity of visited space, its genius loci and/or any cultural and social differences? There are not simply answers for these questions at all. Certainly, virtual guiding has recently developed as a response to the growth of visitors' sophisticated needs and expectations, combined with the common needs of self-invol- 
ving into the creativity as well as experience in their tourist activity. A. Mikos von Rohrscheidt [2012] has compiled and put together the most important expectations of tourists towards guides (or other information emitters) interpreting the urban space of tourist activity. They can be easily combined for each visitor, regardless of the explored space and form of tourist activity. There are:

- confrontation with unicum or genius loci of the destination place;

- $\quad$ identifying the specific interests and expectations of a given group of tourists;

- point to the visitors the message of local history and local stories;

- professional and multi-faceted interpretation;

- $\quad$ need for dialogue and interaction;

- multisensory and varied in form information;

- individualization of the interpretation's offer;

- active and interactive forms of sightseeing;

- linguistic ability and communicative education in languages;

Apart from the classic and still important function of heritage interpreter, there are also two other guides' roles - role of the guide-time-organizer and the role of the guide-animator. Can the above-mentioned needs be satisfied by a virtual form of guidance? Experience and case studies show that it can, although to a different extent for individual elements. The use of appropriate interpretative tools combined with the individual skills as well as communication ability of the interpreter make the virtual guidance a perfect complement to the real one, opening up to new experience and cognitive possibilities. In special cases, it can also replace contact with real guide, although with some limitations. Deficiencies of certain features are, however, replaced with other functions that mostly facilitate communication and interpretation - ignores social and logistic barriers such as: availability, accessibility, seasonality as well as health, economic, political or age-related opportunities.

The interpretation of tourism space is the interpretation of information sent as a signal to the recipient (visitor). This information consists of a package of resources - tourist attractions, cultural values, traditions, symbols and signs and usually is been 'coded' in some way with the appropriate cultural code. The understanding of the code and thus 'decoding' of information needs appropriate knowledge and interpretation skills. In order for the transmitted signal not to be distorted at this stage of reception, an appropriate interpreter or a well-educated and prepared receiver is needed. The signal (information) can also be weakened by a variety of barriers limiting access to information, e.g. lack of accessibility, seasonality, high admission prices or huge queues etc. In this case, the virtual guide is an excellent answer and solution to the existing problem. Communication problems and the transmission of information between the sender (tourism space) and the recipient (visitor) are presented in the Fig.2. It presents possible changes in the reception of the interpreted signal after the introduction of a professional interpreter (Fig. $2 \mathrm{~A}$ ) as well as virtual communication tools (Fig. $2 \mathrm{~B}$ and $2 \mathrm{C}$ ). It is worth noting that the weakening or distortion of information also occurs at the stage of the reception itself. Visitors also have their own cultural code and individual perception abilities which make it difficult to understand the information properly. The use of appropriate interpretation tools (including virtual ones) greatly improves the perception of the received content (Fig. 2C). 
communication emitting space
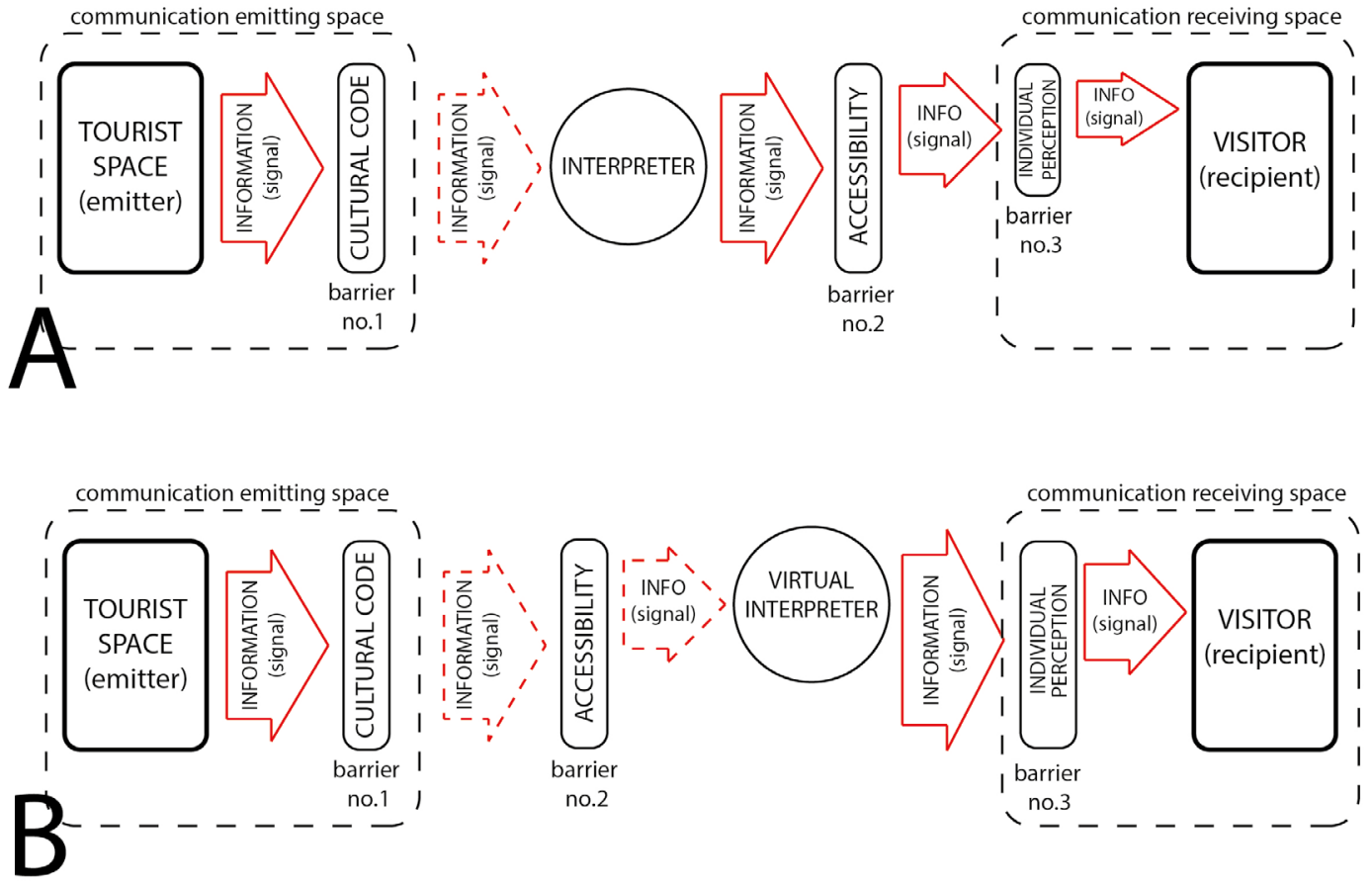

communication emitting space
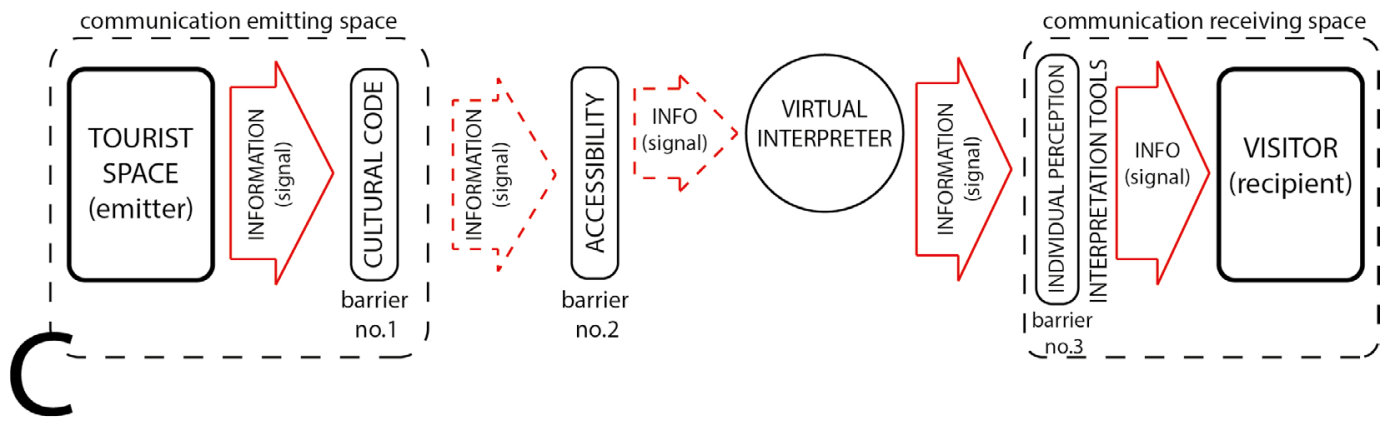

Fig. 2. ( $A, B$ and $C$ ) Communication process - the way of information from emitter (tourist space) to receiver (visitor). A - with professional interpreter, B - with virtual interpreter, $\mathrm{C}$ - with interpretation tools; Source: the author's own work

\section{Virtuality vs. authenticity}

Although the concept of authenticity is not discussed in this publication, its perception is strongly related to the problem of interpretation and guiding. One of the first who raised the issue of authenticity, mainly in psychological as well as social aspects, was Dean MacCannel [1973]. He stated that almost anything 
in today's market is associated with the notion of authenticity. Its connection with the phenomenon of tourism has been developed widely by successive researchers, like e.g. Golomb [1995], Wang [1999], Taylor [2001] or Chhabra [2005]. According to Boyd [2002] the authenticity is regarded to be central to the phenomenon of heritage tourism. Its degree of development serves as the basis for cultural tourism and thus Handler [1986] holds that the search for the authentic cultural experience is based on the unspoiled, pristine, genuine, untouched and traditional.

Originally, the term of authenticity in tourism was used according to museums. Wang [1999] states that this museum-linked definition has been extended to tourism and simplifies the complex nature of authenticity in tourist experience. According to this the issue of authenticity in tourism should be differentiated into two separate ways - that of tourist experiences and that of toured objects. It has been already noticed by Handler and Saxton [1988] and Selwyn [1996] that:

"... experience of 'real world' links to 'authenticity as knowledge' forming so called 'cool authenticity', and analogously - experience of 'real self' to 'authenticity as feeling' - namely 'hot authenticity' (...)" [after: Wang 1999].

As it is shown in global literature, this differentiation related to 'authenticity of experiences' and 'authenticity to toured objects' is crucial for introducing 'existential authenticity' as an alternative, distinctive source for authentic experiences in tourism. It refers to the potential state that could be activated by tourist activities. On the contrary, the object-related authenticity refers to the authenticity of originals. In various tourism types such as nature, landscape, beach, adventures, family or visiting friends, there are their own authentic selves - it links to intersubjective authenticity and "the issue of whether the tour objects are authentic is irrelevant or less relevant" [Wang 1999].

Virtual guiding is often perceived as a substitute tool that does not use the entire spectrum of space experience by users [e.g. Beck, Cable 1998; Mikos von Rohrscheidt 2012, 2014; Smith 2009]. It uses selected elements of the experience, developing them and supplementing with new possibilities as well as technological abilities while decreasing and closing access to others. So how does it affect the perception of destination's authenticity? Does the recipient of the virtual interpretation (virtual visitor) have a chance to experience the uniqueness and authenticity of the "visited" place? Does the lack of physical contact with the environment, a sense of the specific atmosphere of the place (related to the weather, smells, tastes, etc.) deprive the visited space of its authenticity? Taking into account the elements that make up the perception of authenticity and their relationship with the experience of tourism space it, seems that virtual interpretive activity does not significantly reduce the perception of places as authentic. Research conducted among tourists (the results are presented below) has shown that 'cool authenticity' linked to object-related one is preserved to a greater extent than 'hot authenticity' concerning activity-related authenticity. Modern technology allows the use of many tools, including augmented reality, virtual spaces, team games or 3D technology, thanks to which the tourist experiences the destination with all senses, in its original form and with all attractions but without leaving his place as well as paying additional travel costs. Experiencing the genius loci of destination through individual senses or feelings has been replaced by the involvement of "visitors" in the cognitive process through multimedia experiences, competitions and narrative tours. The virtual narrative, however, still presents an authentic place and allows for its unique experience, although through other types of senses and using other areas of reception (Fig.3). 
Fig. 3. Virtuality vs. Authenticity. Source: the author's own work

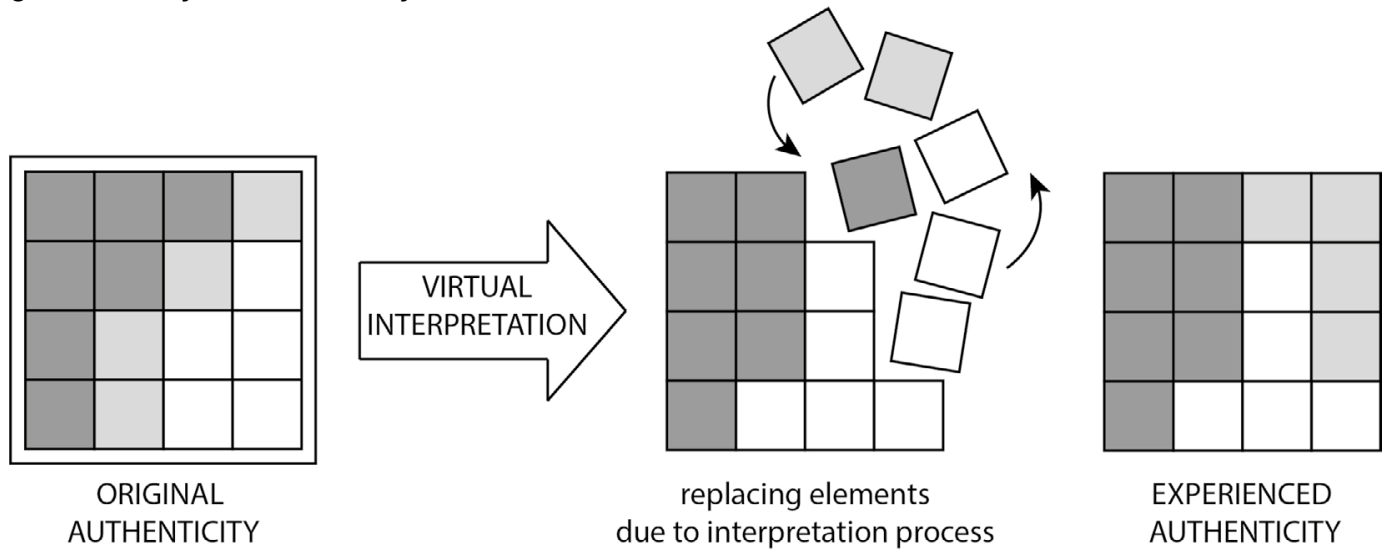

\section{Evaluating virtual guiding - interactive experiences of Polish visitors in Girona}

Until 2020, the virtual interpretation of tourist destinations has been conducted as an alternative, often complementary form of guiding. It influenced the enrichment of information and experience of previously unknown opportunities as well as expanded access to places so far completely inaccessible. To a large extent, virtual communication allowed a group of younger participants to join the tourist activity, whose perception requires new, constantly exposed stimulants. New technologies and attractive forms of narrative reach a wider audience, including specific groups focused on active educational tourism. In 2020, when the world was hit by the global covid-19 pandemic and destinations closed their spaces to tourist activity, virtual guidance became one of only a few possible forms of sightseeing. Its scope, quality and importance in the interpretation process depends only on the creativity of the interpreters themselves and their skills in the field of virtual communication.

To support the theses contained in this publication, the author used his own research on the satisfaction of Polish tourists related to their guided visits in Girona (both real and with the use of virtual technology). The analyzes and observations have been conducted since 2017. Since then, the author (as a tourist guide) has led over a dozen group trips to Girona as well as organized several city sightseeing sessions using interactive technologies. After each trip, the level of tourist satisfaction was tested in relation to several elements:
a) city attractiveness, historical and architectural value, location of objects etc.
b) museums, galleries and other go-inside expositions
c) gastronomy, events, traditions, legends etc.
d) surroundings, nature and environmental elements (e.g. climate, weather)
f) interrelations with the guide - interactivity, involvement, challenges etc.

The level of satisfaction was assessed using the Likert's scale (0-10), where 0-2.5 means 'dissatisfied', 2.5-5 - rather dissatisfied, 5-7.5 - quite satisfied and 7.5-10 - full satisfied. The results are presented in the table below (Tab.1): 
Tab.1. The level of satisfaction among Polish tourists visiting Girona (Catalonia, Spain) during guided tours (real, semi-virtual and virtual) in 2017-2020

\begin{tabular}{|c|c|c|c|}
\hline & $\begin{array}{l}\text { 'real' guided tour visits in } \\
\text { Girona (2017-2019) }\end{array}$ & $\begin{array}{l}\text { using of mobile apps du- } \\
\text { ring visits in Girona (2017- } \\
2019 \text { ) }\end{array}$ & $\begin{array}{l}\text { virtual guided tour to } \\
\text { Girona (using Google } \\
\text { Street View and other } \\
\text { interactive tools) (2020) }\end{array}$ \\
\hline number of tourists & $400-450$ & $100-120$ & $1000-1200$ \\
\hline $\begin{array}{l}\text { satisfaction level } \\
\text { (related to city attractiveness, } \\
\text { historical values, architecture } \\
\text { etc.) }\end{array}$ & $\begin{array}{r}80 \%-8-10 \\
12 \%-6-7 \\
6 \%-3.5-5 \\
2 \%-2-2.5\end{array}$ & $\begin{array}{r}68 \%-8.5-10 \\
16 \%-6-7.5 \\
9 \%-4.5-5 \\
7 \%-2-2.5\end{array}$ & $\begin{array}{r}87 \%-9-10 \\
6 \%-7.5-8.5 \\
5 \%-3.5-4.5 \\
2 \%-2-2.5\end{array}$ \\
\hline $\begin{array}{l}\text { satisfaction level } \\
\text { (related to museums, galle- } \\
\text { ries or other go-inside expo- } \\
\text { sitions) }\end{array}$ & $\begin{array}{r}14 \%-9-10 \\
17 \%-6-7.5 \\
43 \%-4.5-5 \\
26 \%-2-2.5\end{array}$ & $\begin{array}{r}19 \%-8.5-9.5 \\
22 \%-6-7 \\
47 \%-4-5 \\
12 \%-2-2.5\end{array}$ & $\begin{array}{r}47 \%-9-10 \\
38 \%-7.5-8.5 \\
12 \%-4-4.5 \\
3 \%-2-2.5\end{array}$ \\
\hline $\begin{array}{l}\text { satisfaction level } \\
\text { (related to gastronomy, } \\
\text { events, traditions, legends } \\
\text { etc.) }\end{array}$ & $\begin{array}{r}8 \%-7.5-9 \\
3 \%-5.5-7 \\
83 \%-4-5 \\
6 \%-1.5-2.5\end{array}$ & $\begin{array}{r}11 \%-8-9 \\
13 \%-6-7.5 \\
70 \%-4-4.5 \\
6 \%-2-2.5\end{array}$ & $\begin{array}{r}61 \%-9-9.5 \\
22 \%-6-7 \\
14 \%-3-4 \\
3 \%-2-2.5\end{array}$ \\
\hline $\begin{array}{l}\text { satisfaction level } \\
\text { (related to surroundings, na- } \\
\text { ture and environment) }\end{array}$ & $\begin{array}{r}83 \%-9-10 \\
11 \%-7-7.5 \\
5 \%-4.5-5 \\
1 \%-2-2.5\end{array}$ & $\begin{array}{r}51 \%-9-9.5 \\
13 \%-7.5 \\
29 \%-4-5 \\
7 \% 1.5-2.5\end{array}$ & $\begin{array}{r}40 \%-8-8.5 \\
26 \%-6.5-7.5 \\
21 \%-4-4.5 \\
13 \%-2-2.5\end{array}$ \\
\hline $\begin{array}{l}\text { Interrelations with guide - in- } \\
\text { teractivity, involvement, cha- } \\
\text { llenges etc. }\end{array}$ & $\begin{array}{r}81 \%-9-10 \\
17 \%-7.5-8.5 \\
1 \%-4-4.5 \\
1 \%-2-2.5\end{array}$ & $\begin{array}{r}47 \%-9-9.5 \\
26 \%-7.5-8.5 \\
24 \%-3-4.5 \\
3 \%-1.5-2.5\end{array}$ & $\begin{array}{r}69 \%-9-10 \\
14 \%-5.5-7.5 \\
11 \%-3.5-4 \\
6 \%-2-2.5\end{array}$ \\
\hline $\begin{array}{l}\text { Whether and how the use of } \\
\text { interactive (virtual) narrati- } \\
\text { ve and communication tools } \\
\text { changes the perception of a } \\
\text { tourist destination? }\end{array}$ & $\begin{array}{l}57 \% \text { YES: It contributes } \\
\text { to increasing the cognitive } \\
\text { quality of visit } \\
25 \% \text { NO: it does not chan- } \\
\text { ge anything } \\
18 \% \text { YES: it limits the pos- } \\
\text { sibility of interpreting the } \\
\text { destination }\end{array}$ & & \\
\hline
\end{tabular}

\section{Source: author's own work}

The data presented above indicate changes in the perception of destinations as a result of introducing various forms of communication and narrative tools. The indicators of tourist satisfaction during the tour and direct visit to Girona (in 2017-2019), as well as with additional support of virtual tools (Trip Advisor and mobile applications of the city of Girona - e.g. Guia de Girona, Girona App, Gerona, Mirador de la Muralla etc.) as well as during a strictly virtual tour in 2020 were compiled and listed within the table. 
The first visible impact of virtualization in the communication process is the significant increase in the number of visitors. The number of participants in a real trip is limited by the number of places on the bus, plane and available accommodation. During the research period, the author guided around 400-450 people, directly in the urban space of Girona. It should also be emphasized that the time spent visiting the city was very limited (3-4 hours per group), reflecting a clear decrease in satisfaction related to participation in events or using the gastronomic offer. In this situation, a virtual tour is in a better position, when visitors had the opportunity to familiarize themselves with the possibilities of culinary tourism in Girona. This has translated into an increase in the level of satisfaction in this area (Tab.1). In general, the dominance of virtual tools in shaping the level of satisfaction is visible in almost all categories. A slight, although visible decrease in satisfaction is observed in the case of the interpretation of natural values (visitors prefer direct contact with nature, where smells and authenticity of feelings are important) as well as in the case of a direct relationship with the guide.

The results concerning the partial virtualization of guide activity seems to be very interesting. There is a clear increase in interest in applications, especially when it comes to elements that are difficult to access, payable or completely unavailable (museum interiors, galleries and restaurants, including Celler de Can Roca). The impact of mobile applications is only supplementary and does not replace real or even virtual tours themselves.

Finally, all participants in the interpretation were asked the question: Whether and how the use of interactive (virtual) narrative and communication tools changes the perception of a tourist destination? The answers clearly indicate that the virtual guiding significantly improves non-verbal communication and does not affect the negative perception of interpretation. Only $18 \%$ of the respondents believe that direct contact with a guide brings much more benefits from exploring the place than its virtual counterpart. They also believe that virtual tours limit the understanding of space and are not conducive to communication.

\section{Conclusions}

Experience virtualization is a new phenomenon that is developing into a powerful and extremely useful communication tool every year. From an alternative communication tool, related more to fun than real education or the interpretation of destinations, it has become a separate form of expression. Based on new technologies, a new form of interpretation has developed, which is very often used in tourism and guiding. Interpretation of tourism space as well as intercultural communication is one of the most important challenges of contemporary tourism. Tourists' expectations are increasingly focused on individual activity, deeper destinations' experience and building bridges between cultures and borders. The presence of a professional, well-prepared and educated interpreter is therefore an extremely important element of mutual understanding and intercultural communication. It is a kind of 'decoder' that translates the emitter's message so that it is readable and understandable for the recipient (here: visitor). However, it must be made with respect to all the principles of a sustainable dialogue and respect for both sides of communication.

However, while the role of a human being, a guide in interpreting a place, is rather unquestionable, his use of various tools (including virtual and interactive ones) requires a bit more attention. Virtual experience allows, on the one hand, to avoid numerous barriers limiting access to information, and thus the understanding of the destination. On the other hand, it broadens the spectrum of the availability of information without affecting the perception of the authenticity of a place and its unique genius loci. The great ad- 
vantage of new forms of interpretation and communication is also the significant increase of information range. Virtual tools allow also an indefinite number of people to participate in the activity at the same time. However, it carries certain risks and difficulties with the correct 'decoding' of the information provided, as a larger number of recipients increases the chance of a significant diversification of perception and communication capabilities.

As shown by the author's research conducted among tourists visiting Girona, the introduction of virtual tools in the interpretation process not only did not reduce the quality of the provided information, but also increased cognitive and communication capabilities. The only elements that seem irreplaceable are the need for non-verbal contact with another person and the sense of the specific atmosphere of the place destination. These features can never be replaced by any, even the most sophisticated technology.

\section{References:}

- $\quad$ Al Jahwari D.S., Sirakaya-Turk E., Altinas V., 2016, Evaluating communication competency of tour guides using a modified importance-performance analysis (MIPA), International Journal of Contemporary Hospitality Management, vol. 28, no.1, 2016, pp. 195-218

- Banaszkiewicz M., 2011, Kompetencje międzykulturowe w pracy pilotów i przewodników, [in:] Z. Kruczek (ed.) „Piloci i przewodnicy na styu kultur”, wyd. Proksenia, Kraków, pp. 23-40

- Beamer L., 1992, Learning intercultural communication competence, Journal of Business Communication, Vol. 29, No. 3, pp. 285-303

- $\quad$ Beck L., Cable T., 1998, Interpretation for $21^{\text {st }}$ Century. Fifteen guiding principles for interpreting nature and culture, Sagamore Publishing, Champaign/Illinois

- $\quad$ Brochu L, Merriman T., 2008, Personal Interpretation: Connecting Your Audience to Heritage Resources, InterPress $2^{\text {nd }}$, Eds.

- Chhabra D., 2005, Defining Authenticity and its Determinants: Toward an Authenticity Flow Model, Journal of Travel and Research, Vol. 44, pp. 64-73

- Cohen E., 1985, The tourist guide: the origins, structure and dynamics of a role, Annals of Tourism Research, Vol. 12, No. 1, pp. 5-29

- Crosier J.K., Cobb S., Wilson J.R., 2002, Key lessons for the design and integration of virtual environments in secondary science, Computers \& Education 38 (1-3), pp. 77-94

- Dioko L.A.N., Unakul M.H., 2005, The Need for Specialized Training in Heritage Tour Guiding at Asia's World Heritage Sites - Preliminary Findings on the Challenges and Opportunities, Regional Consultation Meeting, Macao

- Golomb J., 1995, In search of authenticity, Routledge, London

- Handler R., Saxton W., 1988, Dissimulation: Reflexivity, Narrative and the Quest for Authenticity in "Living History", Cultural Anthropology 3: 242-260

- Harris L., 1979, Communicative competence: an argument for a systemic view, Annual Conference of the International Communication Association, Philadelphia, PA., 11 November

- $\quad$ Irigüler F., Güler M.E., 2016, Tourist Guiding: "Cinderella" of the Tourism, [in:] C. Avcikurt, M. Dinu (eds.) "Global Issues and Trends in Tourism", St. Kliment Ohridski Univeristy Press, pp. 203-220

- Leclerc D., Martin J.N., 2004, Tour guide communication competence: French, German and American tourists' perceptions, International Journal of Intercultural Relations, Vol. 28, No. 3, pp. 181-200

- $\quad$ Luoh H.F., Tsaur S.H., 2014, The effects of age stereotypes on tour leader roles, Journal of Travel Re- 
search, Vol. 53, No. 1, pp. 111-123

- MacCannell D., 1973, Staged Authenticity: Arrangements of Social Space in Tourist Settings, American Journal of Sociology 79: 589-603

- Mikos von Rohrscheidt A., 2012, Przewodnictwo miejskie w kontekście wyzwań współczesnej turystyki kulturowej, [in:] „Specjalizacja i profesjonalizacja we współczesnym pilotażu i przewodnictwie, Proksenia, Kraków, pp. 55-92

- Mikos von Rohrscheidt A., 2014, Współczesne przewodnictwo miejskie. Metodyka i organizacja interpretacji dziedzictwa, wyd. Proksenia \& Kul.Tour.pl, Kraków

- Rabotić B., 2010, Tourist guide in contemporary tourism, International Conference on Tourism and Environment, Philip Noel-Baker University, Sarajevo, pp. 353-364

- Redmond M., 2000, Cultural distance as a mediating factor between stress and intercultural communication competence, International Journal of Intercultural Relations, Vol. 24, No. 1, pp. 151-159

- $\quad$ Ricard V.B., 1993, Developing Intercultural Communication Skills, Krieger Publishing Company, Malabar, FL

- Selwyn T., 1996, Introduction, [in:] T. Selwyn "The Tourist Image: Myths and Myth Making in Tourism, Wiley, Chichester, pp. 1-32

- $\quad$ Smith M.K., 2009, Issues in Cultural Tourism Studies, Routledge, New York

- $\quad$ Spitzberg B., Cupach W., 1989, Handbook of interpersonal competence research, Springer-Verlag

- Taylor J.P., 2001, Authenticity and Sincerity in Tourism, Annals of Tourism Research, Vol. 33, No. 2, pp. 299-318

- $\quad$ Tilden F., 1957, Interpreting our Heritage: Principles and practices for visitor services in parks, museums and historical places, University of North Carolina Press Chapel Hill

- $\quad$ Ting-Toomey S., 1999, Communicating across cultures, Guilford Press

- Topler J.P., Zubanov V., Gorenak M., Knežević M., 2017, Communication skills in the tourism sector - the role of tour guides in presenting attractions, Turismos: An International Multidisciplinary Journal of Tourism, Vol. 12, No. 1, pp. 57-76

- Vidal C.A., dos Santos E.M., Leite Junior A.J.M., Almendra C.C., Borges V.M.C., 2003, A Tour Guide Course using Collaborative Virtual Environments, XIV Simposio Brasileiro de Informatica na Educacao, NCE

- Wang N., 1999, Rethinking authenticity in tourism experience, Annals of Tourism Research, Vol.26, No. 2, pp. 349-370

- Wijesuriya M.U.E., Mendis S.U., Bandara B.E.S., Mahawattage K.P., Walgampaya N., De Silva D., 2013, Interactive mobile based tour guide, SAITM Research Symposium in Engineering Advancements, 2013, pp. 53-56

- Wilson S., Sabee Ch., 2003, Explicating communicative competence as a theoretical term, [in:] J. Greene, B. Burleson (eds.) "Handbook of communication and social interaction skills", Routledge, pp. 3-51

- Zhang H.Q., Chow I., 2004, Application of importance-performance model in tour guides' performance: evidence from mainland Chinese outbound visitors in Hing Kong, Tourism Management, Vol. 25, No. 1, pp. 81-91 


\section{CURRICULUM VITAE}

Dr Tomasz Duda - researcher and assistant professor at Institute of Spatial Management and Socio-Economic Geography, University of Szczecin in Poland. His researching work focuses on geography of tourism, religious and pilgrimage routes as well as interpretation and guiding of cultural and religious heritage. Member of Editorial Board at the International Journal of Religious Tourism and Pilgrimage and Expert's Collegium in Regional Government Office in Western Pomerania (Poland), concerning cultural routes (e.g. Pomeranian Way of Saint James). Licensed tourist guide and tour-leader with 25 years of experience. Contact mail: tomasz.duda@usz.edu.pl 